\title{
Right ventricular exclusion procedure with total cavopulmonary connection: An alternative operative approach in adults with severe Ebstein anomaly
}

\author{
Anastasios C. Polimenakos, MD, ${ }^{a, b}$ Brian L. Reemtsen, MD, ${ }^{a, b}$ Winfield J. Wells, MD, a,b and Vaughn A. Starnes, MD, \\ Los Angeles, California
}

> bstein anomaly represents less than $1 \%$ of all congenital heart defects. This anomaly affects the tricuspid valve (TV), but also represents a malformation of the right ventricle (RV). ${ }^{1}$

In symptomatic neonates, we found that single-ventricle palliation has its major impact on a combination of a poorly functioning RV, type IV Ebstein anomaly, ${ }^{1}$ and an unguarded TV with RV outflow tract obstruction. ${ }^{2}$ Our experience in older children and adults is similar to that in other published series on valve reconstruction. We describe an unusual presentation of adult Ebstein anomaly that prompted successful single-ventricle palliation.

\section{Clinical Summary}

A 19-year-old man with a diagnosis of symptomatic severe Ebstein anomaly and previous atrial septal defect device closure underwent a combined total cavopulmonary connection with fenestrated RV exclusion technique and explantation of the Amplatzer (AGA Medical Corp, Golden Valley, Minn) occlusion device. Before the implantation of the occlusion device, the patient was experiencing worsening cyanosis and exercise intolerance. Post-intervention, he presented with increasing frequency of palpitations and shortness of breath with activity. Severely limited exercise capacity was demonstrated by the treadmill stress test. Before the palliative procedure, echocardiography demonstrated the TV with the septal leaflet attachments displaced far apically, +2 TV insufficiency, almost completely atrialized intact ventricular septum, and septal bowing far leftward during diastole compromising the diastolic and systolic left ventricular (LV) function (Figure 1). A cardiac catheterization indicated a favorable pulmonary vascular resistance to accommodate a total cavopulmonary connection.

After a standard bicaval venous cannulation, the patient was placed on cardiopulmonary bypass and cooled to $32^{\circ} \mathrm{C}$. A standard

From the Children's Hospital Los Angeles, ${ }^{\text {a }}$ Los Angeles, Calif; and the University of Southern California Keck School of Medicine, ${ }^{\mathrm{b}}$ Los Angeles, Calif.

Received for publication Aug 27, 2007; accepted for publication Oct 15, 2007.

Address for reprints: Anastasios C. Polimenakos, MD, Children's Hospital Los Angeles, Cardiothoracic Surgery, 4650 W. Sunset Blvd, Mailbox \#66, Los Angeles, CA 90027 (E-mail: anapolisis@aol.com).

J Thorac Cardiovasc Surg 2008;135:1182-3

$0022-5223 / \$ 34.00$

Copyright $\odot 2008$ by The American Association for Thoracic Surgery doi:10.1016/j.jtcvs.2007.10.074 bidirectional Glenn was performed to the right pulmonary artery. A 22-mm polytetrafluoroethylene (Gore-Tex; WL Gore \& Associates, Inc, Flagstaff, Ariz) tube was anastomosed to the medial aspect of the inferior surface of the right pulmonary artery. The aorta was crossclamped, and the heart was arrested using antegrade cold cardioplegia. An oblique right atriotomy incision was performed, and the Amplatzer occlusion device was explanted leaving a nonrestrictive atrial septal defect. The TV annular orifice was excluded with a fenestrated (4-mm punch-hole) bovine pericardial patch. Right atrial free wall reduction was performed via excision. After right atriotomy closure, the anastomosis of the polytetrafluoroethylene (Gore-Tex) tube to the inferior vena cava was completed. Aortic crossclamp and cardiopulmonary bypass times were 25 and 64 minutes, respectfully.

Postoperatively, no selective pulmonary vasodilation was required, and the mean pulmonary pressure never exceeded $15 \mathrm{~mm}$ $\mathrm{Hg}$. The pleural chest tubes were uneventfully removed on day 4 . The patient was discharged the following day with diuretics and an afterload-reduction agent. At the 2-month follow-up, the patient showed New York Heart Association class I, had a decreased cardiothoracic ratio on chest $\mathrm{X}$-ray, and showed no evidence of recurrent pleural effusion and RV involution with decreased septal impingement into the LV, as indicated by echocardiography (Figure 2).

\section{Discussion}

Although TV reconstruction or replacement is the preferred surgical strategy in extreme forms of Ebstein anomaly with a deteriorating clinical picture, the results are often less than optimal. ${ }^{3}$

The concept of combined TV reconstruction, plication of atrialized RV, and bidirectional Glenn is associated with improved exercise tolerance, decreased RV end-diastolic volume index, and improved LV ejection fraction and stroke volume. The bidirectional Glenn procedure contributed in preventing further RV dilation and decreasing RV end-diastolic volume. ${ }^{4}$ Excising the entire RV free wall followed by patch reconstruction has been recommended by others. ${ }^{5}$ Prolonged duration of cardiopulmonary bypass and crossclamp time can compromise patients already deconditioned by biventricular failure.

Our experience in neonatal severe Ebstein anomaly, when a fenestrated RV exclusion technique is applied, shows normalization of the systemic ventricle morphology and function. ${ }^{2}$ Our early and intermediate results indicate that unloading of the $\mathrm{RV}$ with gradual regression of the septal impingement into the LV takes place in the early postoperative period without the need for extensive RV free wall resection or plication.

Older patients with an extreme form of Ebstein anomaly and $\mathrm{RV}$ outflow tract obstruction or pulmonary atresia may benefit 


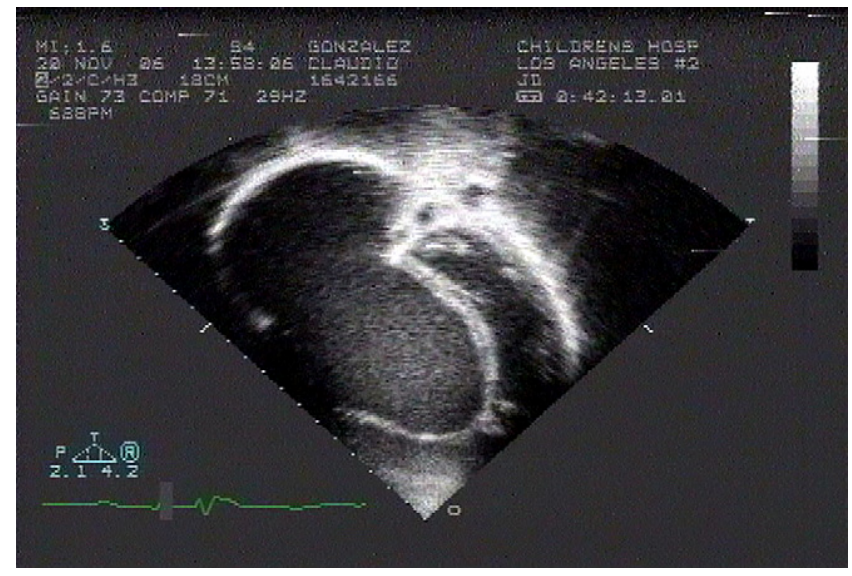

Figure 1. Preoperative echocardiogram: Almost completely atrialized intact ventricular septum is noted. The septal bowing far leftward during diastole compromises the left ventricular function.

from single-ventricle palliation. We have described the complex ventricular interplay and systemic failure in neonates. ${ }^{2}$ This interplay exists in adult patients with extreme Ebstein anomaly. The fenestrated RV exclusion may mitigate against the substrate for a poor 2-ventricle repair and persistent septal impingement of the systemic ventricle.

TV reconstruction with or without a bidirectional Glenn shunt may be proposed for the case presented here. In adult patients, this procedure has been associated with a high incidence of reoperation because of valve failure. ${ }^{3} \mathrm{~A}$ fenestrated RV exclusion with total cavopulmonary connection offers an alternative approach with remarkable hemodynamic outcome in selected adult cases with severe Ebstein anomaly.

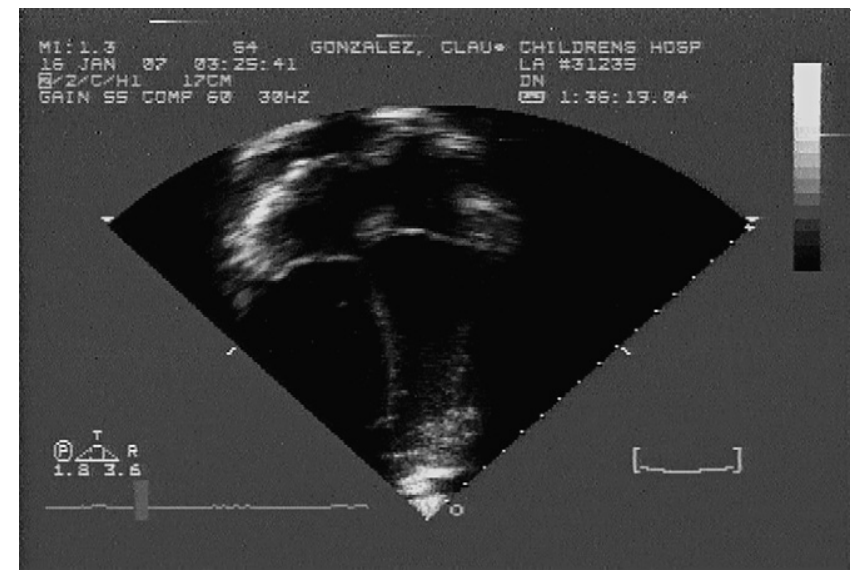

Figure 2. Two-month follow-up echocardiogram: Right ventricular involution with decreased septal impingement into the left ventricle is noted.

\section{References}

1. Dearani JA, Danielson GK. Surgical management of Ebstein anomaly in the adult. Semin Thorac Cardiovasc Surg. 2005;17:148-54.

2. Reemtsen BL, Fagan BT, Wells WJ, Starnes VA. Current therapy for Ebstein anomaly in neonates. $J$ Thorac Cardiovasc Surg. 2006;132:1285-90.

3. Boston US, Dearani JA, O'Leary PW, Driscoll DJ, Danielson GK. Tricuspid valve repair for Ebstein anomaly in young children. Ann Thorac Surg. 2006;81:690-5.

4. Marianeschi SM, McElhinney DB, Reddy VM, Silverman NH, Hanley FL. Alternative approach to the repair of Ebstein malformation: intracardiac repair with ventricular unloading. Ann Thorac Surg. 1998;66:1546-50.

5. Sano S, Ishiro K, Kawada M, Kasahara S, Kohmoto T, Takeuchi M, et al. Total right ventricular exclusion procedure: an operation for isolated congestive right ventricular failure. J Thorac Cardiovasc Surg. 2002; 123:640-7. 